Article

\title{
A Rapid Antigen Detection Test to Diagnose SARS-CoV-2 Infection Using Exhaled Breath Condensate by A Modified Inflammacheck ${ }^{\circledR}$ Device
}

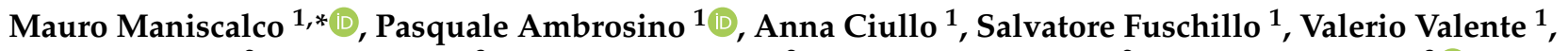 \\ Carlo Gaudiosi ${ }^{2}$, Debora Paris ${ }^{3}$, Raffaele Cobuccio ${ }^{2}$, Francesco Stefanelli ${ }^{2}$ and Andrea Motta ${ }^{3}$ (i) \\ 1 Istituti Clinici Scientifici Maugeri IRCCS, 27100 Pavia, Italy; pasquale.ambrosino@icsmaugeri.it (P.A.); \\ anna.ciullo@icsmaugeri.it (A.C.); salvatore.fuschillo@icsmaugeri.it (S.F.); Valerio.valente@icsmaugeri.it (V.V.) \\ 2 Department of Respiratory Medicine, Boscotrecase Covid Hospital, 80042 Boscotrecase, Italy; \\ c.gaudiosi@aslnapoli3sud.it (C.G.); pobosc.pneumo@aslnapoli3sud.it (R.C.); \\ f.stefanelli@aslnapoli3sud.it (F.S.) \\ 3 Institute of Biomolecular Chemistry, National Research Council, ICB-CNR, 80078 Pozzuoli, Italy; \\ debora.paris@icb.cnr.it (D.P.); andrea.motta@icb.cnr.it (A.M.) \\ * Correspondence: mauro.maniscalco@icsmaugeri.it
}

\section{check for}

updates

Citation: Maniscalco, M.;

Ambrosino, P.; Ciullo, A.; Fuschillo,

S.; Valente, V.; Gaudiosi, C.; Paris, D.;

Cobuccio, R.; Stefanelli, F.; Motta, A.

A Rapid Antigen Detection Test to

Diagnose SARS-CoV-2 Infection

Using Exhaled Breath Condensate by

A Modified Inflammacheck ${ }^{\circledR}$ Device.

Sensors 2021, 21, 5710. https:/ /

doi.org/10.3390/s21175710

Academic Editor: Hyoun Woo Kim

Received: 12 July 2021

Accepted: 20 August 2021

Published: 25 August 2021

Publisher's Note: MDPI stays neutral with regard to jurisdictional claims in published maps and institutional affiliations.

Copyright: (c) 2021 by the authors. Licensee MDPI, Basel, Switzerland. This article is an open access article distributed under the terms and conditions of the Creative Commons Attribution (CC BY) license (https:// creativecommons.org/licenses/by/ $4.0 /)$.

\begin{abstract}
Background: The standard test that identifies the severe acute respiratory syndrome coronavirus-2 (SARS-CoV-2) is based on reverse transcriptase-polymerase chain reaction (RT-PCR) from nasopharyngeal (NP) swab specimens. We compared the accuracy of a rapid antigen detection test using exhaled breath condensate by a modified Inflammacheck ${ }^{\circledR}$ device with the standard RT-PCR to diagnose SARS-CoV-2 infection. Methods: We performed a manufacturer-independent, cross-sectional, diagnostic accuracy study involving two Italian hospitals. Sensitivity, specificity, positive (PLR) and negative likelihood ratio (NLR), positive (PPV) and negative predictive value (NPV) and diagnostic accuracy with 95\% confidence intervals (95\% CI) of Inflammacheck ${ }^{\circledR}$ were calculated using the RT-PCR results as the standard. Further RT-PCR tests were conducted on NP specimens from test positive subjects to obtain the $\mathrm{Ct}$ (cycle threshold) values as indicative evidence of the viral load. Results: A total of 105 individuals (41 females, 39.0\%; 64 males, $61.0 \%$; mean age: 58.4 years) were included in the final analysis, with the RT-PCR being positive in $13(12.4 \%)$ and negative in 92 (87.6\%). The agreement between the two methods was $98.1 \%$, with a Cohen's $\mathrm{k}$ score of 0.91 (95\% CI: 0.79-1.00). The overall sensitivity and specificity of the Inflammacheck ${ }^{\circledR}$ were $92.3 \%$ (95\% CI: 64.0\%-99.8\%) and 98.9\% (95\% CI: 94.1\%-100\%), respectively, with a PLR of 84.9 (95\% CI: 12.0-600.3) and a NLR of 0.08 (95\% CI: 0.01-0.51). Considering a 12.4\% disease prevalence in the study cohort, the PPV was $92.3 \%$ (95\% CI: 62.9\%-98.8\%) and the NPV was 98.9\% (95\% CI: 93.3\%-99.8\%), with an overall accuracy of $98.1 \%$ (95\% CI: 93.3\%-99.8\%). The Fagan's nomogram substantially confirmed the clinical applicability of the test in a realistic scenario with a pre-test probability set at $4 \%$. Ct values obtained for the positive test subjects by means of the RT-PCR were normally distributed between 26 and 38 cycles, corresponding to viral loads from light (38 cycles) to high (26 cycles). The single false negative record had a $\mathrm{Ct}$ value of 33, which was close to the mean of the cohort (32.5 cycles). Conclusions: The modified Inflammacheck ${ }^{\circledR}$ device may be a rapid, non-demanding and cost-effective method for SARS-CoV-2 detection. This device may be used for routine practice in different healthcare settings (community, hospital, rehabilitation).
\end{abstract}

Keywords: COVID-19; SARS-CoV-2; exercise; disability; rehabilitation; outcome

\section{Introduction}

The new severe acute respiratory syndrome coronavirus-2 (SARS-CoV-2) first appeared in December 2019, and it subsequently spread rapidly worldwide causing a global pandemic [1]. When symptoms are experienced, infected patients develop the coronavirus 
disease 2019 (COVID-19) [2]. To effectively reduce the spread of the infection in addition to containment measures, sensitive, specific, rapid, inexpensive and easy-to-use tests able to rule out or to confirm SARS-CoV-2 infection, possibly even in the asymptomatic phase of the infection, are welcomed.

Before SARS-CoV-2 infection manifests itself, there is usually an incubation period lasting up to 14 days, with a median of approximately 5 days from exposure to symptom onset [3]. The early identification of suspected cases represents a key strategy to control the spread and the mortality rate of the infection. Therefore, rapid, effective and costless diagnostic tests should be implemented with large-scale automated diagnostic equipment.

Currently, the reference standard test accepted for identification of SARS-CoV-2 positive subjects is based on molecular assays detecting viral RNA by reverse transcriptasepolymerase chain reaction (RT-PCR) from nasopharyngeal (NP) swabs [4]. Most diagnostic molecular tests have been approved by the United States Food and Drug Administration under emergency use authorization (EUA) and are Conformité Européenne marked [5]. These assays target various genes that include spike (S) surface glycoprotein, small envelope (E) protein, nucleocapsid (N) protein and RNA-dependent RNA polymerase (ORF1ab) [6]. To enhance test sensitivity and specificity, it has been suggested to target at least two genes [7]. However, a NP swab negative result does not necessarily rule out infection. In subjects with a negative NP swab but with a high clinical suspicion for COVID-19, to resolve the diagnostic doubt, it may be required to sample from the lower respiratory tract [8]. Molecular tests usually require qualified personnel and specialised laboratory equipment and are burdened by the potential exposure to the virus of healthcare professionals who take and process the biological samples. Definitely, the cumbersome procedures necessary for the diagnosis of SARS-CoV-2 infection represent in themselves an additional burden of the pandemic.

SARS-CoV-2 may spread via small droplets in breath and aerosols [9] and there is evidence supporting the presence of the virus in exhaled breath condensate (EBC). Breath droplets with aerodynamic diameter lower than $5 \mu \mathrm{m}$ are collected by EBC rendering it a suitable matrix for SARS-CoV-2 detection [10]. The angiotensin converting enzyme-2 (ACE-2) protein has been recognized as an important binding protein for SARS-CoV-2, allowing the virus to enter cells [11]. Therefore, a test detecting the virus in EBC by exploiting its ability to bind this protein may be a useful tool for a rapid diagnosis. The modified Inflammacheck ${ }^{\circledR}$ device is a novel, hand-held, fully automated in vitro diagnostic medical device for non-invasive detection of SARS-CoV-2 in exhaled breath at point of care. It integrates the safe collection of EBC with an automated platform for SARS-CoV-2 detection through an embedded electrochemical sensor. The sensor surface is coated with a macromolecule to which the virus binds, producing a measurable signal indicating whether SARS-CoV-2 is present or not. The test assay renders a result after less than $6 \mathrm{~min}$. EBC is collected by the Inflammacheck ${ }^{\circledR}$ device through normal breathing, making this investigation non-invasive, rapid, reliable and easy to perform. The aim of our study was to compare the diagnostic sensitivity and specificity of the Inflammacheck ${ }^{\circledR}$ device for SARS-CoV-2 detection with the standard RT-PCR of NP swab specimens.

\section{Materials and Methods}

We carried out a cross-sectional multicentre study across two independent hospitals of Campania Region in Italy, namely Pulmonary Rehabilitation Unit of Istituti Clinici Scientifici Maugeri Spa SB, IRCCS of Telese Terme, Benevento, and Boscotrecase Hospital, Boscotrecase, Naples. We enrolled four groups of patients at different stages of the diagnostic/screening process for potential SARS-CoV-2 infection: group 1, subjects with clinically suspected COVID-19; group 2, convalescent COVID-19 patients undergoing pulmonary rehabilitation for persistent pulmonary and/or functional limitations within four weeks from acute hospital discharge; group 3, asymptomatic subjects with a high probability of SARS-CoV-2 infection; group 4, asymptomatic subjects with a low probability of SARS-CoV-2 infection. The level of clinical suspect was established by physicians, 
based on the presence/absence of typical COVID-19 symptoms (i.e., fever, dry cough, shortness of breath, lethargy, myalgia, arthralgia) and of compatible radiological findings on chest X-ray or chest computed tomography (CT) scans. The major inclusion criteria were age $\geq 18$ years and informed consent signature. Exclusion criteria were: invasive or non-invasive ventilation, high-flow oxygen, symptomatic hypoxia or oxygen saturation $\leq 92 \%$ ( $\leq 88 \%$ in chronic obstructive pulmonary disease) despite oxygen supplementation at $4 \mathrm{~L} / \mathrm{min}$ via nasal cannula, suspicion of alcohol or drug abuse or any other condition associated with poor compliance in the investigator's opinion. The study was approved by the Institutional Review Board of Istituto Nazionale Tumori, Fondazione Pascale, Naples, Italy with reference number $2 / 21$. All patients provided written informed consent.

\subsection{RT-PCR Swabs}

RT-PCR was performed as the reference standard on the same day of the index test using the NeuMoDx ${ }^{\mathrm{TM}} 300800$ (Qiagen, Hilden, Germany), with results inferred according to the manufacturer's specifications. The NeuMoDx ${ }^{\mathrm{TM}}$ SARS-CoV-2 assay is an automated sample-to-answer assay that received emergency use authorization from the FDA. It is a multiplex assay targeting two regions of the viral genome, namely Nsp2 and the N genes. The NeuMoDx ${ }^{\mathrm{TM}}$ System automatically performs all the steps required to extract the target nucleic acid and prepare the isolated RNA for RT-PCR and, if present, amplifies and detects target sequences of the Nsp2 N genes. The NeuMoDx ${ }^{\mathrm{TM}}$ System uses a combination of heat, lytic enzyme and extraction reagents to automatically perform lysis, RNA extraction and removal of inhibitors using the separately available NeuMoDx ${ }^{\mathrm{TM}}$ reagents. The released nucleic acids are captured by paramagnetic particles. The particles, with bound nucleic acid, are loaded into the "NeuMoDx ${ }^{\mathrm{TM}}$ Cartridge where the unbound elements are washed away with NeuMoDx ${ }^{\mathrm{TM}}$ Wash Reagent". The bound RNA is then eluted using NeuMoDx ${ }^{\mathrm{TM}}$ Release Reagent. The NeuMoDx ${ }^{\mathrm{TM}}$ System uses the eluted RNA to rehydrate proprietary NeuDry ${ }^{\mathrm{TM}}$ amplification RT-PCR mix containing all the elements necessary for amplification of both SARS-CoV-2 and sample process control (SPC2) targets. The amplified targets are detected in real time using hydrolysis probe chemistry (commonly referred to as TaqMan ${ }^{\mathrm{TM}}$ chemistry) using fluorogenic oligonucleotide probe molecules specific to the amplicons of their respective targets. TaqMan ${ }^{\mathrm{TM}}$ probes are designed such that they anneal within a DNA region amplified by a specific set of primers. The Nsp2 region is detected by means a TaqMan ${ }^{\mathrm{TM}}$ probe labeled with a FAM fluorophore $(470 / 510 \mathrm{~nm})$ while the N gene is detected by using a TaqMan ${ }^{\mathrm{TM}}$ probe labeled with a HEX fluorophore $(530 / 555 \mathrm{~nm})$. A TaqMan ${ }^{\mathrm{TM}}$ probe labeled with a Far-Red fluorophore $(680 / 715 \mathrm{~nm})$ is used for SPC2 detection. When amplification is complete, the NeuMoDx ${ }^{\mathrm{TM}}$ System software analyzes the data and expresses the result as positive if one or both target genes have been detected, and as negative if both target genes are not amplified while SPC2 is, as undetermined in the case of an instrumental error or, finally, as unresolved in the case of the instrument's inability to express a valid result. Quantification of the viral RNA load was achieved by employing the comparative threshold cycle (Ct) method. $\mathrm{Ct}$ is defined as the PCR cycle at which the accumulated amount of PCR product achieves an arbitrary threshold. This method allows for precise determination of the viral RNA load in a sample, relative to that of a positive control with known viral RNA load by comparing the $\mathrm{Ct}$ of the sample and the positive control included in the PCR assay kit.

\subsection{Inflammacheck ${ }^{\circledR}$}

When testing with the Inflammacheck ${ }^{\circledR}$, the subject breathes into a disposable breath collection unit, which is mounted in the Inflammacheck ${ }^{\circledR}$ device (Exhalation technology LTD, Cambridge, UK). The breath collection unit is sealed off towards the rest of the Inflammacheck ${ }^{\circledR}$ system to mitigate the risk of cross-infection. It is composed of a sensor cartridge with a built-in single-use sensor, a valve house directing the airflow through the system and a bacterial viral filter. The filter serves to filter ambient air before it is inhaled, as well as to filter exhaled breath before it leaves the breath collection unit. To perform 
a test, the Inflammacheck ${ }^{\circledR}$ is switched on, and the breath collection unit is inserted. It has an embedded RFID tag containing information on the sensor and sensor cartridge, including manufacturing batch and dates, which is read by the device and stored along with the test data establishing traceability in the system. The device performs a self-check to ensure the system is fully functional and capable of performing a test, and then initiates cooling by means of a Peltier element to bring down the temperature at the condensation area to below $6{ }^{\circ} \mathrm{C}$. When this temperature has been reached, the device emits a beep and tells the subject to start breathing through the mouthpiece of the breath collection unit. When exhaling, the subject breathes onto a condensation area, which is part of the sensor cartridge, to form a test sample of EBC. During sample collection, EBC builds up in the condensation area until enough has been collected $(20-30 \mu \mathrm{L}$, which typically forms in $45-90$ s). Then it automatically flows into a sensor capillary. The device monitors the fill of the sensor capillary to ensure an adequate amount of sample is present to perform a test. Upon registered fill, the device emits a beep and instructs the subject to stop collecting the sample and place the device on a table. The device automatically proceeds into the analytical assay. The device performs a first test scan to establish a baseline pre-curve, and then proceeds into a $5 \mathrm{~min}$ incubation period where the virus, if present in the EBC, binds to the macromolecule coated sensor surface. After incubation, a second test scan is performed to build a post-curve. The presence of virus is determined by comparing preand post-curves. Less than $6 \mathrm{~min}$ after fill detection, the test result is presented back to the operator/test subject via the built-in display on the device (Figure 1).

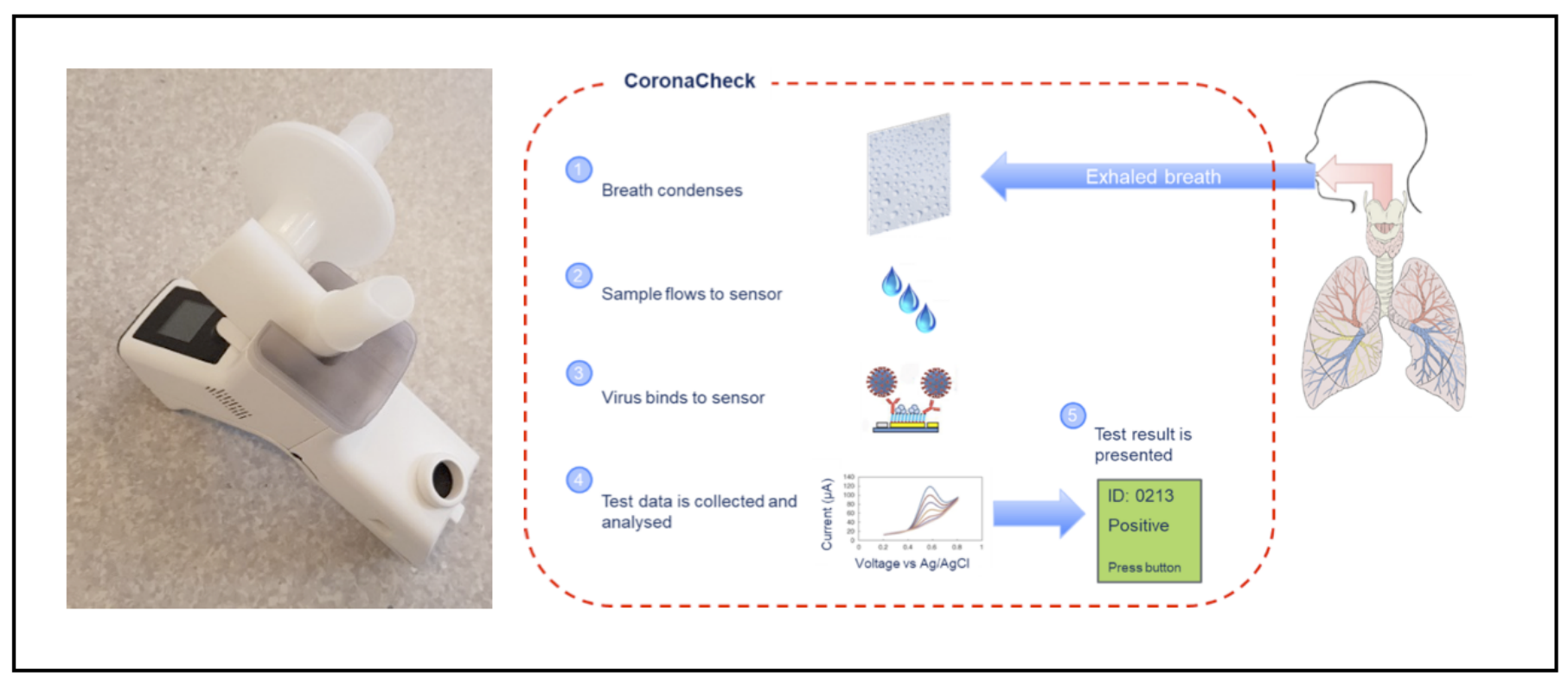

Figure 1. The Inflammacheck ${ }^{\circledR}$ device and its operating mechanism.

After use, the test consumable is disposed of in a safe bin. The sample collected is contained inside the disposable test consumable, thereby mitigating the risk of contamination between samples as well as the risk of a test subject being exposed to residuals of samples from previous test subjects. The reader device itself is wiped off between tests with $70 \%$ alcohol to further mitigate the risk of cross-infection between test subjects.

\subsection{Statistics}

Sensitivity, specificity, positive (PLR) and negative likelihood ratio (NLR), positive (PPV) and negative predictive value (NPV) and diagnostic accuracy with 95\% confidence intervals $(95 \% \mathrm{CI})$ of Inflammacheck ${ }^{\circledR}$ were calculated using the RT-PCR results as standard. The level of agreement between the tests was evaluated using the Cohen's K score [12]. Diagnostic performance results were stratified by age and gender. Statistical analysis was 
performed with R Statistical software (R Core Team 2021). Fagan's nomogram was used to estimate post-test probability from likelihood ratios and evaluate the clinical applicability of the device.

\section{Results}

Of 119 patients screened for eligibility, six $(5.0 \%)$ were ineligible for protocol adherence issues. Four (3.4\%) refused to participate in the study. A total of four (3.7\%) out of the 109 eligible patients were not considered because measurement failed due to technical problems. Thus, 66 participants from Istituti Clninci Scientifici Maugeri and 39 from Boscotrecase Covid Hospital entered the study. Overall, a total of 105 individuals (41 females, 39.0\%; 64 males, $61.0 \%$; mean age 58.4 years) were included in the final analysis, of which 21 (20.0\%) were subjects with clinically suspected COVID-19 (group 1), $20(19.0 \%)$ convalescent COVID-19 patients (group 2), 14 (13.3\%) were asymptomatic participants with a high clinical probability of SARS-CoV-2 infection (group 3) and 50 (47.6\%) were asymptomatic participants with a low clinical probability of SARS-CoV-2 infection (group 4) (Table 1).

Table 1. Study cohort included in the validation study of the Inflammacheck ${ }^{\circledR}$ device.

\begin{tabular}{cc}
\hline Total Number of Valid RT-PCR Tests & $\mathbf{1 0 5}$ \\
\hline Positive RT-PCR, $n(\%)$ & $13(12.4)$ \\
Age (years) & $58.4 \pm 14.4$ \\
Female gender (\%) & $41(39.0)$ \\
Clinically suspected COVID-19, $n(\%)$ & $21(20.0)$ \\
Convalescent COVID-19, $n(\%)$ & $20(19.0)$ \\
Asymptomatic with high clinical probability, $n(\%)$ & $14(13.3)$ \\
Asymptomatic with low clinical probability, $n(\%)$ & $50(47.6)$ \\
\hline
\end{tabular}

RT-PCR: Reverse transcriptase-polymerase chain reaction; COVID-19: coronavirus disease 2019; $n$ : number.

Among the 105 subjects, RT-PCR was positive in 13 (12.4\%) and negative in 92 (87.6\%). One 57-year-old male participant tested positive with RT-PCR but negative with the Inflammacheck ${ }^{\circledR}$ device. A further discrepancy was a 31-year-old woman who tested a false positive on Inflammacheck ${ }^{\circledR}$. Thus, similarly to RT-PCR, the test performed with the Inflammacheck ${ }^{\circledR}$ device was positive in $13(12.4 \%)$ cases and negative in $92(87.6 \%)$ cases in our study sample (Table 2).

Table 2. Summary of the results of the Inflammacheck ${ }^{\circledR}$ device compared to standard RT-PCR from nasopharyngeal swab specimens.

\begin{tabular}{cccc}
\hline RT-PCR & Positive & $\begin{array}{c}\text { Inflammacheck }^{\circledR} \text { Device } \\
\text { Negative }\end{array}$ & Total \\
\hline Positive & 12 & 1 & 13 \\
Negative & 1 & 91 & 92 \\
Total & 13 & 92 & $\mathbf{1 0 5}$ \\
\hline
\end{tabular}

We also extracted and recorded Ct values from the NeuMoDx ${ }^{\mathrm{TM}}$ System (Table 3) obtained for the positive test subjects to assess viral load. The $\mathrm{Ct}$ values were distributed normally between 26 and 38 cycles, with a mean of 32.5 cycles. This was assessed to correspond to viral loads ranging from light (38 cycles) to high ( 26 cycles). The single false negative record had a $\mathrm{Ct}$ value of 33 that was close to the mean of the cohort.

Based on these data, the agreement between the two methods was $98.1 \%$, with a Cohen's k score of 0.91 (95\% CI: $0.79-1.00)$. The overall sensitivity and specificity of the Inflammacheck ${ }^{\circledR}$ were $92.3 \%$ (95\% CI: 64.0\%-99.8\%) and 98.9\% (95\% CI: 94.1\%-100\%), respectively, with a PLR of 84.9 (95\% CI: 12.0-600.3) and an NLR of 0.08 (95\% CI: 0.01-0.51). Considering a $12.4 \%$ disease prevalence in the study cohort, the PPV was $92.3 \%$ (95\% CI: $62.9 \%-98.8 \%$ ) and the NPV was $98.9 \%$ (95\% CI: $93.3 \%-99.8 \%)$, with a diagnostic accuracy of 
98.1\% (95\% CI: 93.3\%-99.8\%). Since PPV, NPV and diagnostic accuracy can vary depending on prevalence data, these three indicators were also estimated in a realistic scenario reflecting the SARS-CoV-2 positivity rate in Italy at the time of the examination. Thus, with an estimated 4\% disease prevalence, the PPV and the NPV were 78.0\% (95\% CI: $33.4 \%-96.2 \%$ ) and $99.6 \%$ (95\% CI: 97.9\%-99.9\%), respectively, with an overall accuracy of $98.6 \%(95 \%$ CI: $94.1 \%-99.9 \%)$. Accordingly, based on likelihood ratios and the pre-test probability set at $4 \%$, the Fagan's nomogram confirmed that the post-test probability increased to $78 \%$ if the patient tested positive and decreased to $0.4 \%$ in case of a negative result with the Inflammacheck ${ }^{\circledR}$ device (Figure 2).

Table 3. Summary of the results of the $\mathrm{Ct}$ values of each positive subject included in the study obtained with NeuMoDx ${ }^{\mathrm{TM}}$ System. Age and gender included for statistical reasons.

\begin{tabular}{ccccc}
\hline Positive Subject & Age & Gender & Study Group & Ct Value \\
\hline 1 & 76 & Female & 1 & 33 \\
2 & 70 & Male & 1 & 28 \\
3 & 49 & Male & 1 & 33 \\
4 & 41 & Male & 1 & 32 \\
5 & 78 & Male & 1 & 31 \\
6 & 54 & Male & 1 & 38 \\
7 & 65 & Male & 1 & 26 \\
8 & 68 & Male & 3 & 28 \\
9 & 59 & Female & 1 & 34 \\
10 & 74 & Male & 3 & 38 \\
11 & 44 & Male & 1 & 37 \\
13 & 57 & Male & 1 & 33 \\
\hline
\end{tabular}

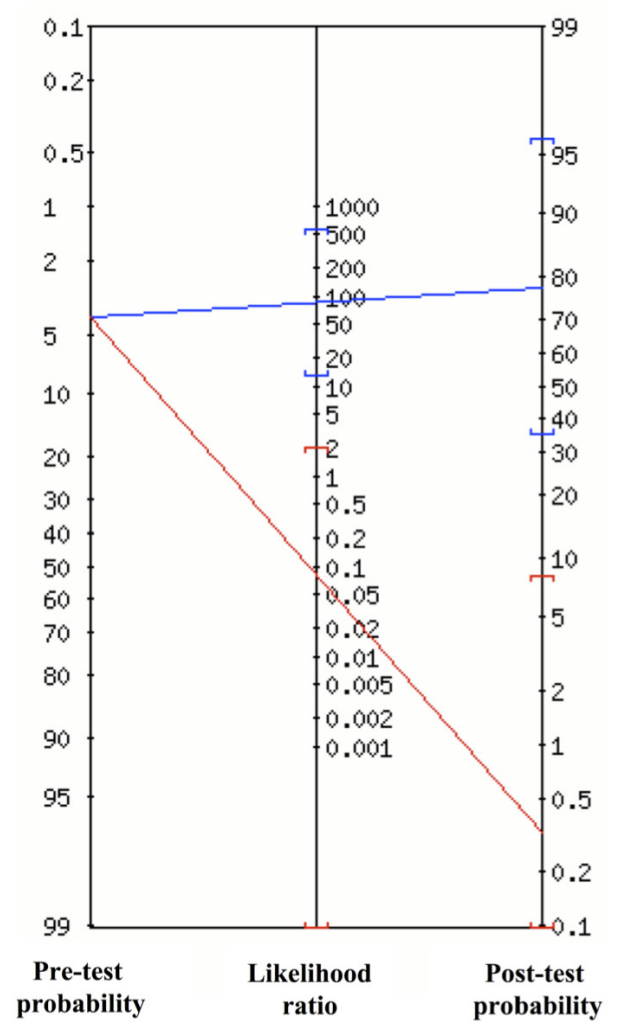

Change in probability if positive test

Change in probability if negative test

Figure 2. Fagan's nomogram from positive (PLR) and negative likelihood ratio (NLR). 
Table 4 shows results stratified by age and gender. Given the relatively low number of participants, no definite conclusion could be drawn in this regard.

Table 4. Estimation of clinical performance of the Inflammacheck ${ }^{\circledR}$ device compared to standard reverse transcriptase-polymerase chain reaction (RT-PCR) from nasopharyngeal swab specimens.

\begin{tabular}{|c|c|c|}
\hline & Value & $95 \%$ CI \\
\hline \multicolumn{3}{|l|}{ Total cohort $(n=105)$} \\
\hline Sensitivity & $92.3 \%$ & $64.0 \%$ to $99.8 \%$ \\
\hline Specificity & $98.9 \%$ & $94.1 \%$ to $100 \%$ \\
\hline Positive Likelihood Ratio & 84.9 & 12.0 to 600.3 \\
\hline Negative Likelihood Ratio & 0.08 & 0.01 to 0.51 \\
\hline Positive Predictive Value & $92.3 \%$ & $62.9 \%$ to $98.8 \%$ \\
\hline Negative Predictive Value & $98.9 \%$ & $93.3 \%$ to $99.8 \%$ \\
\hline Accuracy & $98.1 \%$ & $93.3 \%$ to $99.8 \%$ \\
\hline Cohen's k score & 0.91 & 0.79 to 1.00 \\
\hline \multicolumn{3}{|l|}{ Females $(n=41)$} \\
\hline Sensitivity & $100 \%$ & $15.8 \%$ to $100 \%$ \\
\hline Specificity & $97.4 \%$ & $85.5 \%$ to $99.9 \%$ \\
\hline Positive Likelihood Ratio & 39.0 & 5.6 to 270.0 \\
\hline Negative Likelihood Ratio & 0 & - \\
\hline Positive Predictive Value & $66.7 \%$ & $22.4 \%$ to $93.3 \%$ \\
\hline Negative Predictive Value & $100 \%$ & - \\
\hline Accuracy & $97.6 \%$ & $87.1 \%$ to $99.9 \%$ \\
\hline Cohen's K score & 0.79 & 0.39 to 1.00 \\
\hline \multicolumn{3}{|l|}{ Males $(n=64)$} \\
\hline Sensitivity & $90.9 \%$ & $58.7 \%$ to $100 \%$ \\
\hline Specificity & $100 \%$ & $93.3 \%$ to $100 \%$ \\
\hline Positive Likelihood Ratio & - & - \\
\hline Negative Likelihood Ratio & 0.09 & 0.01 to 0.59 \\
\hline Positive Predictive Value & $100 \%$ & $62.9 \%$ to $98.8 \%$ \\
\hline Negative Predictive Value & $98.1 \%$ & $89.1 \%$ to $99.7 \%$ \\
\hline Accuracy & $98.4 \%$ & $91.6 \%$ to $100 \%$ \\
\hline Cohen's k score & 0.94 & 0.83 to 1.00 \\
\hline \multicolumn{3}{|l|}{$\geq 65$ years $(n=42)$} \\
\hline Sensitivity & $100 \%$ & $47.8 \%$ to $100 \%$ \\
\hline Specificity & $100 \%$ & $90.5 \%$ to $100 \%$ \\
\hline Positive Likelihood Ratio & - & - \\
\hline Negative Likelihood Ratio & 0 & - \\
\hline Positive Predictive Value & $100 \%$ & - \\
\hline Negative Predictive Value & $100 \%$ & - \\
\hline Accuracy & $100 \%$ & $91.6 \%$ to $100 \%$ \\
\hline Cohen's k score & 1.00 & - \\
\hline \multicolumn{3}{|l|}{$<65$ years $(n=63)$} \\
\hline Sensitivity & $87.5 \%$ & $47.3 \%$ to $99.7 \%$ \\
\hline Specificity & $98.2 \%$ & $90.3 \%$ to $99.9 \%$ \\
\hline Positive Likelihood Ratio & 48.1 & 6.8 to 341.5 \\
\hline Negative Likelihood Ratio & 0.13 & 0.02 to 0.81 \\
\hline Positive Predictive Value & $87.5 \%$ & $49.7 \%$ to $98.0 \%$ \\
\hline Negative Predictive Value & $98.2 \%$ & $89.6 \%$ to $99.7 \%$ \\
\hline Accuracy & $96.8 \%$ & $89.6 \%$ to $99.7 \%$ \\
\hline Cohen's k score & 0.86 & 0.67 to 1.00 \\
\hline
\end{tabular}

\section{Discussion}

Results of our preliminary study suggest that the modified Inflammacheck ${ }^{\circledR}$ device, as compared to NeuMoDx ${ }^{\mathrm{TM}}$ System RT-PCR NP swab, identifies SARS-CoV-2 in EBC excellently, with sensitivity and specificity of $92.3 \%$ and $98.9 \%$, respectively. Moreover, the 
analysis of the likelihood ratios and the Fagan's nomogram suggest that the test could be considered suitable for routine practice.

Currently, RT-PCR assay represents the gold standard for diagnosis of SARS-CoV-2 infection and can be performed on nasopharyngeal and oropharyngeal swabs in symptomatic and asymptomatic people. However, RT-PCR analysis is time consuming and requires dedicated laboratory equipment and personnel specifically trained. Up to $54 \%$ of COVID-19 patients may test negative on the initial NP swab samples RT-PCR [13]. Such a high rate of false negatives results from several causes among which the most frequent are methodological errors with inadequate sample collection, errors in sampling times or errors in the handling and shipment of the sample [14]. In addition, it has been reported that certain deletions/mutations in the SARS-CoV-2 genome can affect PCR performance [15]. It is now clear that infected subjects can transmit the virus during the asymptomatic phase of infection, the viral load peak occurring one or two days before onset of symptoms [16]. After the appearance of COVID-19 symptoms, the percentage of success of the NP swab detection progressively decreases over time. In a study by Wölfel et al, all swabs taken between day 1 and day 5 tested positive, while after five days of symptoms the detection rate dropped up to $40 \%$ [17]. Current evidence supports the feasibility of detecting SARSCoV-2 RNA in EBC by RT-PCR testing for the diagnosis of COVID-19 within two days of disease onset in spontaneously breathing subjects [9]. In a study by Ryan et al [18], it was reported that after a median number of seven symptomatic days (range 2-20), depending on the type and number of the viral genome regions targeted, the success detection rate of SARS-CoV-2 by RT-PCR in EBC was between $66.6 \%$ and $93.3 \%$ of NS-negative patients with a clinical diagnosis of COVID-19. Negative results of two consecutive molecular assays from respiratory specimens more than $24 \mathrm{~h}$ apart have been the suggested key strategy for discontinuation of transmission [4]. However, SARS-CoV-2 RNA can be detectable for weeks after the onset of symptoms and this does not necessarily indicate the presence of infectious virus $[19,20]$. Because asymptomatic infected subjects are frequent and, as compared to symptomatic patients, carry out a similar viral load in respiratory specimens [21], they could represent the main culprits of the epidemiologic worsening of the pandemic [22]. Consequently, the availability of a rapid and sensitive test for the detection of SARS-CoV-2 would overcome the diagnostic uncertainty and allow for the rapid implementation of infectious prevention measures in different healthcare settings (i.e., community, hospital, rehabilitation) [23-25]. The results we present here indicate that Inflammacheck ${ }^{\circledR}$ permits a non-invasive detection of SARS-CoV-2 with high sensitivity and specificity in less than $6 \mathrm{~min}$. In addition, EBC collection does not require manipulation of the sample as it is collected by the device itself through normal breathing, making this investigation non-invasive, rapid, reliable and easy to perform. Collecting EBC specimens has several advantages over NP swabs, among which are a lower risk of viral spread and/or environmental contamination and, above all, minimal training is required and the method can be carried out by anyone. In addition, EBC sampling can repeatedly be performed as many times as needed in follow-up investigations. Thanks to the social measures implemented and the availability of effective vaccines, the pandemic epidemiological curve has progressively improved. However, the abolition of social restrictions, together with the resumption of international travel as well as the appearance of new viral variants make the rapidity and specificity of diagnostic tests extremely important to identify and isolate in a very short time all infected subjects in the asymptomatic phase.

A major limitation of our study should be addressed. In detail, a diagnostic accuracy study should ideally enroll a random or consecutive sample of eligible patients with the suspected condition to avoid the case-control design and, therefore, a potential bias. Thus, studies enrolling patients with the target condition and a control group without it may overestimate diagnostic accuracy. Moreover, our choice of enrolling four patient groups at different stages of the diagnostic/screening process for potential SARS-CoV-2 infection accounts for the different pre-test probability and, therefore, for the impossibility of performing sensitivity or subgroup analyses other than those related to major demo- 
graphic variables. Overall, caution is required in interpreting our results, which should be considered preliminary.

\section{Conclusions}

Our preliminary results demonstrate that Inflammacheck ${ }^{\circledR}$ enables the qualitative detection of SARS-CoV-2 in EBC samples in a reliable manner, with excellent overall, positive and negative percentage agreements and with a high $\mathrm{k}$ value. Owing to its simplicity and high sensitivity, Inflammacheck ${ }^{\circledR}$ is particularly suited in the triage process and for a rapid screening of a large population, which would be useful at airports, on college campuses, drive-through screening clinics, shopping centres, train stations, point of care facilities, etc. However, the results we presented should be validated in a larger cohort study, and the performance of the device in differentially diagnosing SARS-CoV-2 from similar respiratory viruses should also be checked.

Author Contributions: Conceptualization, M.M. and P.A.; methodology, M.M. and P.A.; validation, S.F., V.V. and F.S.; formal analysis, P.A. and S.F.; investigation, M.M., F.S., C.G. and A.C.; data curation, A.C. and C.G.; writing—original draft preparation, A.M., D.P. and R.C.; writing-review and editing, M.M., P.A., S.F. and R.C.; supervision, A.M. and F.S.; project administration, A.M. All authors have read and agreed to the published version of the manuscript.

Funding: No funding were received for the study.

Institutional Review Board Statement: The study was approved by the Institutional Review Board of Istituto Nazionale Tumori, Fondazione Pascale, Naples, Italy with reference number 2/21.

Informed Consent Statement: Informed consent was obtained from all subjects involved in the study.

Data Availability Statement: The data supporting the findings of this study are available from the corresponding authors upon reasonable request.

Acknowledgments: We thank Giorgio Alfredo Spedicato for technical support. Giorgio Alfredo Spedicato provided written permission to be included in the acknowledgments section of this manuscript.

Conflicts of Interest: The authors declare that there are no competing interests associated with the manuscript. The Inflammacheck ${ }^{\circledR}$ device and consumables were donated by Exhalation Technology Ltd. (www.exhalationtechnology.com, Cambridge CB5 8EP, United Kingdom, accessed on 31 July 2021) to the research team for validating the instrument, but the Company and the authors have no other commercial and/or scientific relationships. Finally, Exhalation Technology Ltd. had no role, in study design, collection, analysis and interpretation of data, writing of the manuscript and the decision to submit it for publication.

\section{References}

1. Zhu, H.; Wei, L.; Niu, P. The novel coronavirus outbreak in Wuhan, China. Glob. Health Res. Policy 2020, 5, 6. [CrossRef]

2. Lovato, E.C.W.; Barboza, L.N.; Wietzikoski, S.; de Souza, A.N.V.; Auth, P.A.; Junior, A.G.; Dos Reis Livero, F.A. Repurposing Drugs for the Management of Patients with Confirmed Coronavirus Disease 2019 (COVID-19). Curr. Pharm. Des. 2021, 27, 115-126. [CrossRef]

3. Lauer, S.A.; Grantz, K.H.; Bi, Q.; Jones, F.K.; Zheng, Q.; Meredith, H.R.; Azman, A.S.; Reich, N.G.; Lessler, J. The Incubation Period of Coronavirus Disease 2019 (COVID-19) From Publicly Reported Confirmed Cases: Estimation and Application. Ann. Intern. Med. 2020, 172, 577-582. [CrossRef]

4. CDC. Interim Guidelines for Collecting, Handling, and Testing Clinical Specimens from Persons for Coronavirus Disease 2019_COVID-19. Available online: https:/ /www.cdc.gov/coronavirus/2019-ncov/lab/guidelines-clinical-specimens.html (accessed on 23 August 2021).

5. Vijayan, T.; Klausner, J.D. Hepatitis C: Challenges and opportunities in the laboratory diagnosis of infection. MLO Med. Lab. Obs. 2016, $48,18$.

6. Udugama, B.; Kadhiresan, P.; Kozlowski, H.N.; Malekjahani, A.; Osborne, M.; Li, V.Y.C.; Chen, H.; Mubareka, S.; Gubbay, J.B.; Chan, W.C.W. Diagnosing COVID-19: The Disease and Tools for Detection. ACS Nano 2020, 14, 3822-3835. [CrossRef]

7. Tang, Y.W.; Schmitz, J.E.; Persing, D.H.; Stratton, C.W. Laboratory Diagnosis of COVID-19: Current Issues and Challenges. J. Clin. Microbiol. 2020, 58, e00512-20. [CrossRef] [PubMed] 
8. Bhimraj, A.; Morgan, R.L.; Shumaker, A.H.; Lavergne, V.; Baden, L.; Cheng, V.C.; Edwards, K.M.; Gandhi, R.; Muller, W.J.; O’Horo, J.C.; et al. Infectious Diseases Society of America Guidelines on the Treatment and Management of Patients with COVID-19. Clin. Infect. Dis. 2020, ciaa478. [CrossRef] [PubMed]

9. Sawano, M.; Takeshita, K.; Ohno, H.; Oka, H. RT-PCR diagnosis of COVID-19 from exhaled breath condensate: A clinical study. J. Breath Res. 2021, 15, 037103. [CrossRef] [PubMed]

10. Khoubnasabjafari, M.; Jouyban-Gharamaleki, V.; Ghanbari, R.; Jouyban, A. Exhaled breath condensate as a potential specimen for diagnosing COVID-19. Bioanalysis 2020, 12, 1195-1197. [CrossRef] [PubMed]

11. Zhang, H.; Penninger, J.M.; Li, Y.; Zhong, N.; Slutsky, A.S. Angiotensin-converting enzyme 2 (ACE2) as a SARS-CoV-2 receptor: Molecular mechanisms and potential therapeutic target. Intensive Care Med. 2020, 46, 586-590. [CrossRef]

12. McHugh, M.L. Interrater reliability: The kappa statistic. Biochem. Med. 2012, 22, 276-282. [CrossRef]

13. Arevalo-Rodriguez, I.; Buitrago-Garcia, D.; Simancas-Racines, D.; Zambrano-Achig, P.; Del Campo, R.; Ciapponi, A.; Sued, O.; Martinez-Garcia, L.; Rutjes, A.W.; Low, N.; et al. False-negative results of initial RT-PCR assays for COVID-19: A systematic review. PLoS ONE 2020, 15, e0242958. [CrossRef] [PubMed]

14. Di Paolo, M.; Iacovelli, A.; Olmati, F.; Menichini, I.; Oliva, A.; Carnevalini, M.; Graziani, E.; Mastroianni, C.M.; Palange, P. False-negative RT-PCR in SARS-CoV-2 disease: Experience from an Italian COVID-19 unit. ERJ Open Res. 2020, 6, 00324-2020. [CrossRef] [PubMed]

15. Artesi, M.; Bontems, S.; Gobbels, P.; Franckh, M.; Maes, P.; Boreux, R.; Meex, C.; Melin, P.; Hayette, M.P.; Bours, V.; et al. A Recurrent Mutation at Position 26340 of SARS-CoV-2 Is Associated with Failure of the E Gene Quantitative Reverse TranscriptionPCR Utilized in a Commercial Dual-Target Diagnostic Assay. J. Clin. Microbiol. 2020, 58, e01598-20. [CrossRef]

16. He, X.; Lau, E.H.Y.; Wu, P.; Deng, X.; Wang, J.; Hao, X.; Lau, Y.C.; Wong, J.Y.; Guan, Y.; Tan, X.; et al. Temporal dynamics in viral shedding and transmissibility of COVID-19. Nat. Med. 2020, 26, 672-675. [CrossRef] [PubMed]

17. Wolfel, R.; Corman, V.M.; Guggemos, W.; Seilmaier, M.; Zange, S.; Muller, M.A.; Niemeyer, D.; Jones, T.C.; Vollmar, P.; Rothe, C.; et al. Virological assessment of hospitalized patients with COVID-2019. Nature 2020, 581, 465-469. [CrossRef] [PubMed]

18. Ryan, D.J.; Toomey, S.; Madden, S.F.; Casey, M.; Breathnach, O.S.; Morris, P.G.; Grogan, L.; Branagan, P.; Costello, R.W.; De Barra, E.; et al. Use of exhaled breath condensate (EBC) in the diagnosis of SARS-COV-2 (COVID-19). Thorax 2021, 76, 86-88. [CrossRef]

19. Sethuraman, N.; Jeremiah, S.S.; Ryo, A. Interpreting Diagnostic Tests for SARS-CoV-2. JAMA 2020, 323, 2249-2251. [CrossRef]

20. Sohn, Y.; Jeong, S.J.; Chung, W.S.; Hyun, J.H.; Baek, Y.J.; Cho, Y.; Kim, J.H.; Ahn, J.Y.; Choi, J.Y.; Yeom, J.S. Assessing Viral Shedding and Infectivity of Asymptomatic or Mildly Symptomatic Patients with COVID-19 in a Later Phase. J. Clin. Med. 2020, 9, 2924. [CrossRef]

21. Zou, L.; Ruan, F.; Huang, M.; Liang, L.; Huang, H.; Hong, Z.; Yu, J.; Kang, M.; Song, Y.; Xia, J.; et al. SARS-CoV-2 Viral Load in Upper Respiratory Specimens of Infected Patients. N. Engl. J. Med. 2020, 382, 1177-1179. [CrossRef]

22. Bai, Y.; Yao, L.; Wei, T.; Tian, F.; Jin, D.Y.; Chen, L.; Wang, M. Presumed Asymptomatic Carrier Transmission of COVID-19. JAMA 2020, 323, 1406-1407. [CrossRef] [PubMed]

23. Ambrosino, P.; Papa, A.; Maniscalco, M.; Di Minno, M.N.D. COVID-19 and functional disability: Current insights and rehabilitation strategies. Postgrad. Med. J. 2021, 97, 469-470. [CrossRef] [PubMed]

24. Struble-Fitzsimmons, D.; Feld-Glazman, R.; Dominick, E.; Alexandrou, S.; Rider, E.; Bogosian, C.; Norton, J.; Pacheco, L.; Andreassi, E. A Retrospective Quality Improvement Study to Describe Operational Management Strategies in an Inpatient Rehabilitation Facility during the COVID-19 Pandemic. Arch. Phys. Med. Rehabil. 2021, in press. [CrossRef] [PubMed]

25. Zhu, Y.; Wang, Z.; Zhou, Y.; Onoda, K.; Maruyama, H.; Hu, C.; Liu, Z. Summary of respiratory rehabilitation and physical therapy guidelines for patients with COVID-19 based on recommendations of World Confederation for Physical Therapy and National Association of Physical Therapy. J. Phys. Ther. Sci. 2020, 32, 545-549. [CrossRef] [PubMed] 